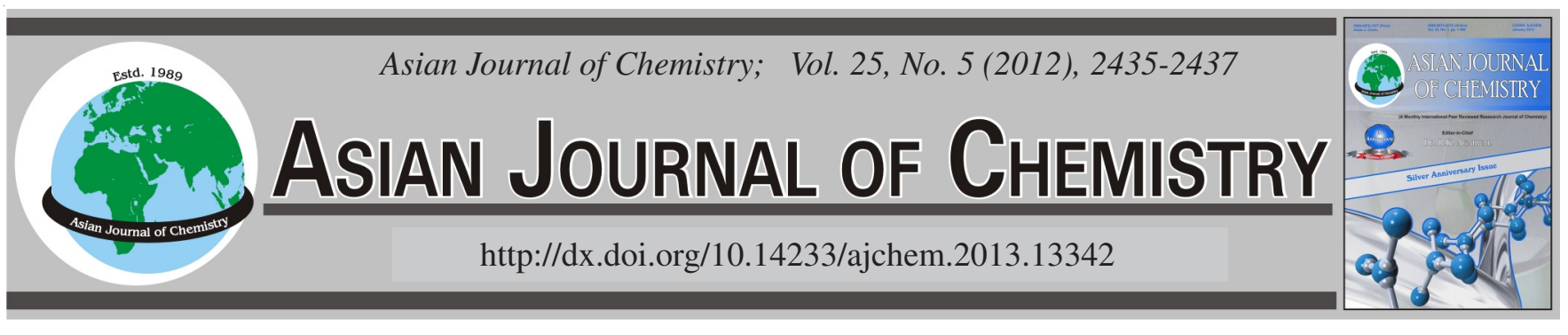

\title{
Regional Differentiation by Lead Isotope Ratios in Different Soil Fractions
}

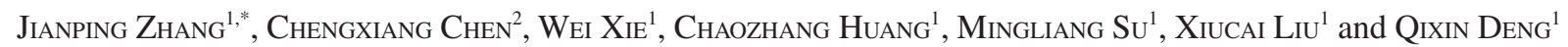

${ }^{1}$ Technical Center, China Tobacco Fujian Industrial Corporation, Xiamen 361000, P.R. China

${ }^{2}$ Analytical Science Laboratory of Huaxia University, Xiamen 361000, P.R. China

*Corresponding author: Tel: +86 592 6560155; E-mail: zhangjp@fjtic.cn; goose821120@126.com

(Received: 27 December 2011;

Accepted: 7 November 2012)

AJC-12375

The isotopic ratios of lead vary with geographic locations. In this study, lead isotopic ratios of soil from different regions in Fujian Province are determined by inductively coupled plasma mass spectrometry, the differences of lead isotopic $\operatorname{ratios}\left({ }^{206} \mathrm{~Pb} /{ }_{207} \mathrm{~Pb},{ }^{206} \mathrm{~Pb} /{ }^{208} \mathrm{~Pb}\right)$ in the total digests of soil fractions and in that of the residual fractions were compared. The results show that lead isotopic ratios of residual fraction are more efficient than that of total digests of soil fractions in identifying sources of soil.

Key Words: Inductively coupled plasma mass spectrometry, Lead isotopic ratios, Soil, Regional differentiation.

\section{INTRODUCTION}

Lead has four natural isotopes including ${ }^{204} \mathrm{~Pb},{ }^{206} \mathrm{~Pb},{ }^{207} \mathrm{~Pb}$, ${ }^{208} \mathrm{~Pb}$. ${ }^{204} \mathrm{~Pb}$ is always used as a stable checking isotope because of its long $1.4 \times 10^{17}$ half life, while ${ }^{206} \mathrm{~Pb},{ }^{207} \mathrm{~Pb}$ and ${ }^{208} \mathrm{~Pb}$ keep changing in abundance because they are disintegration products of $\mathrm{U}$ and $\mathrm{Th}$. The variety of lead isotope can be accurately measured by mass spectrum, as a result, it is used as a racer in environmental process ${ }^{1,2}$. Barnes and Amarasiriwardena ${ }^{3}$ measured lead isotopic ratios in ten types of druggery containing calcium. Zhiyong et al. ${ }^{4}$ measured lead isotopic ratios in Danshen (one of traditional Chinese medicinal herb) from different regions ${ }^{4}$. Cheng and Foland ${ }^{5}$ measured lead isotopic ratios in tap water from Columbus. All of the results validate the feasibility to distinguish source by lead isotopic ratios.

The diversity in geological configuration, geologicalage, mineral content and in region precipitation distributing brings different lead isotopic ratios in different regions, which is called isotopic signature. As lead isotopic ratios has clime character, we can use inductively coupled plasma mass spectrometry (ICP-MS) to measure it accurately and then identify the source of the soil. However, the clime character of the solid may be blurred as the problem of solid pollution becomes worse and worse due to the development of the industry and agriculture ${ }^{6-8}$. In order to investigate the problem, this study, respectively measure the lead isotopic ratios of soil from different regions in Fujian Province in total digests fractions and residual fractions.

\section{EXPERIMENTAL}

HP4500 ICP-MS (Agilent); MK-II FDDI model microwave-assisted digestion oven fitted with an optical fiber pressure controlling system (manufactured by the Institute of XiCo Micro-wave Technology, Shanghai); MiniQ purify installation.

Natural lead isotopes standard SRM981 and enriched lead isotopes standard SRM982 (US nation standard); $1000 \mu \mathrm{g} / \mathrm{mL}$ Tl standard repertory GSBG62070-90(8101) (nation steel material testing center), high-purity deionized water obtained from a MilliQ water $(\geq 18 \mathrm{M} \Omega$ ) is used for solutions preparation and dilution. All other chemical reagent are high purity grade.

All the glassware are all dipped in $10 \% \mathrm{HNO}_{3}$ for more than $24 \mathrm{~h}$. Twenty-three samples of soil from different regions of Fujian province, including samples 1 and 2 from WuYi Mountain, sample 3 and 4 from Jian'Ou, samples 5 and 6 from FuDing, samples 7-9 from A tobacco base in Fu'An, samples 10-13 from B tobacco base in Fu'An, samples 14, 15 from AnXi, Samples 16, 17 from Long Yan, samples 18-20 from Zhang Pu, samples 21-23 from Fu Zhou.

Working conditions of ICP-MS: $10 \mu \mathrm{g} / \mathrm{L} \mathrm{Li}, \mathrm{Y}, \mathrm{Ce}, \mathrm{Tl}$ mixed standard solution is used to optimize instrumental conditions and data acquisition parameters are shown in Table-1.

Sample preparation: In this experiment we adopt $\mathrm{HNO}_{3}$ $\mathrm{HClO}_{4}$-HF microwave digests system. All the 23 shares of soil samples from different regions of Fujian province are digested in residual fractions after serial Tessier extraction and in total digests fractions.

About $0.1 \mathrm{~g}$ powdery sample is digested in $50 \mathrm{~mL}$ sealed PTFE vessel with $4 \mathrm{~mL} \mathrm{HNO}_{3}, 1 \mathrm{~mL} \mathrm{HClO}_{4}$ and $1 \mathrm{~mL} \mathrm{HF}$ by microwave digestion oven for $10 \mathrm{~min}$ and then was heated up on galvanothermy board to drive acid to neary dry, put in $1 \mathrm{~mL}$ $40 \mathrm{mg} / \mathrm{L} \mathrm{H}_{3} \mathrm{BO}_{3}$ and drive again. Finally, the digested is diluted with $2 \% \mathrm{HNO}_{3}$. 
TABLE-1

INSTRUMENTAL CONDITIONS AND DATA ACQUISITION PARAMETERS OF ICP-MS

\begin{tabular}{lccc}
\hline \multicolumn{1}{c}{ Parametes } & Value & Parameters & Value \\
\hline RF power & $1200 \mathrm{~W}$ & Sample uptake rate & $1.0 \mathrm{~mL} / \mathrm{min}$ \\
Sampling depth & $6.5 \mathrm{~mm}$ & Acquisition mode & Isotopes rate analysis \\
Plama gas & $16.0 \mathrm{~L} / \mathrm{min}$ & Points/mass & 3 \\
Auxiliary gas & $1.00 \mathrm{~L} / \mathrm{min}$ & No. of sweeps & 1000 \\
Carrier gas & $1.00 \mathrm{~L} / \mathrm{min}$ & Scan mode & Skip apex \\
Diameter of sampler & $1.0 \mathrm{~mm}$ & Dwell time & ${ }^{206} \mathrm{~Pb},{ }^{207} \mathrm{~Pb} 10 \mathrm{~ms} ;{ }^{208} \mathrm{~Pb} 5 \mathrm{~ms}$ \\
Diameter of skimmer & $0.8 \mathrm{~mm}$ & No. of replicates & 3 \\
\hline
\end{tabular}

Method: Measure the lead isotopic ratios $\left({ }^{206} \mathrm{~Pb} /{ }^{207} \mathrm{~Pb}\right.$, $\left.{ }^{206} \mathrm{~Pb} /{ }^{208} \mathrm{~Pb}\right)$ in total digests fractions and residual fractions under the condiction of ICP-MS.

\section{RESULTS AND DISCUSSION}

Precision: As disintegration products of radio element, ${ }^{206} \mathrm{~Pb},{ }^{207} \mathrm{~Pb},{ }^{208} \mathrm{~Pb}$ have changing abundance in nature world. But in most cases, lead isotopic ratios vary only in a few small ranges. The range from $1.95-2.15$ for ${ }^{208} \mathrm{~Pb} /{ }^{206} \mathrm{~Pb}$, from 0.78 0.86 for ${ }^{207} \mathrm{~Pb} /{ }^{206} \mathrm{~Pb}$ and from $0.05-0.06$ for ${ }^{204} \mathrm{~Pb} /{ }^{206} \mathrm{~Pb}$. The average range of the ratios is $\pm 5, \pm 10$ and $\pm 10 \%$ for ${ }^{208} \mathrm{~Pb}$ / ${ }^{206} \mathrm{~Pb},{ }^{207} \mathrm{~Pb} /{ }^{206} \mathrm{~Pb}$ and ${ }^{204} \mathrm{~Pb} /{ }^{206} \mathrm{~Pb}$, respectively. In order to distinguish solid samples from different regions, the relative standard derivation (RSD \%) of the measurement is prescribed to be less than $\pm 0.5 \%$ for the ratios of ${ }^{208} \mathrm{~Pb} /{ }^{206} \mathrm{~Pb}$ and $\pm 1 \%$ for ${ }^{207} \mathrm{~Pb} /{ }^{206} \mathrm{~Pb}$ and ${ }^{204} \mathrm{~Pb} /{ }^{206} \mathrm{~Pb}$.

Considering the importance of precision in the isotopic ratio measurement, the precision tests are carried out with 50 $\mu \mathrm{g} / \mathrm{L}$ SRM982 Pb solution. The results are shown in Table-2.

\begin{tabular}{cccc}
\multicolumn{4}{c}{ TABLE-2 } \\
\multicolumn{4}{c}{ PRECISION OF Pb ISOTOPE RATIOS WITH ICP-MS } \\
\hline $\begin{array}{c}\text { Measuring } \\
\text { time }(\mathrm{n})\end{array}$ & ${ }^{206} \mathrm{~Pb} /{ }^{208} \mathrm{~Pb}$ & ${ }^{206} \mathrm{~Pb} /{ }^{207} \mathrm{~Pb}$ & ${ }^{206} \mathrm{~Pb} /{ }^{204} \mathrm{~Pb}$ \\
\hline 12 & $\mathrm{RSD}(\%)$ & $\mathrm{RSD}(\%)$ & $\mathrm{RSD}(\%)$ \\
\hline 6 & 0.14 & 0.13 & 0.55 \\
3 & 0.15 & 0.13 & 0.59 \\
\hline
\end{tabular}

Influence of the lead concentration in the experiment: In the experiment using ICP-MS to measure the ratio of lead isotopes, an optimal sample solution concentration must be chosen for two reasons: first of all, the statistic date measured by low concentration isotopes ratios is large and the error can be described by the formula

$$
\operatorname{RSD}(\%)=100 \times \sqrt{\frac{1}{\mathrm{~N}_{\mathrm{a}}}+\frac{1}{\mathrm{~N}_{\mathrm{b}}}}
$$

in which $\mathrm{N}_{\mathrm{a}}$ and $\mathrm{N}_{\mathrm{b}}$, respectively refer to the numerical value of isotope $\mathrm{A}$ and that of $\mathrm{B}$. From the equation, we can know that the lower the concentration of lead is, the bigger the error will be. Secondly, the check mode of ICP-MS must be considered. ICP-MS will adopt simulation mode automatically if the ion signal reaches $6,000,000 \mathrm{p} / \mathrm{s}$. And it uses simulation mode to measure ${ }^{208} \mathrm{~Pb}$ with high abundance when the concentration of lead comes up to a certain extent, but uses impulse mode to measure other isotopes with low abundance. A bigger error will still exist though the two modes have been revised when we optimized the apparatus. Considering the great varity of lead concentration in samples, it is necessary to verify the impact of different lead concentrations in measuring lead isotopic ratios. We measure the $2-150 \mu \mathrm{g} / \mathrm{L} \mathrm{SRM982} \mathrm{and} \mathrm{its}$ standard deviation which are $0.28 \%\left({ }^{206} \mathrm{~Pb} /{ }^{208} \mathrm{~Pb}\right), 0.24 \%$ $\left({ }^{206} \mathrm{~Pb} /{ }^{207} \mathrm{~Pb}\right)$ and $1.4 \%\left({ }^{206} \mathrm{~Pb} /{ }^{204} \mathrm{~Pb}\right)$. From the experiment, we used ICP-MS to measure the isotopic ratios.

Analysis process: The processes to analyze the sample: 1. Pre-scan the sample and estimate the concentration range. If the concentration is too high, dilute it with purified water to make sure the three isotopes' measurement all use impulse measure mode. 2 . Analyse the sample and then add $0.1 \mathrm{~mL} 50$ $\mathrm{mg} / \mathrm{L} \mathrm{Tl}$ standard liquor to every sample to revise the mass discrimination.

Pb isotopic ratios of samples: The lead istope ratios ${ }^{206} \mathrm{~Pb} /$ ${ }^{208} \mathrm{~Pb}$ and ${ }^{206} \mathrm{~Pb} /{ }^{207} \mathrm{~Pb}$ of total digests of soil fractions from different regions are measured by HP4500 ICP-MS with the isotope ratio analytic method. The results are shown in Fig. 1, from which the distribution of $\mathrm{Pb}$ isotopic ratios of total digests of soil fractions from eight regions can be distinguished on the whole. Generally speaking, the lead isotopic ratios similarity of different regions is in inverse proportion to the distance, e.g., the average ${ }^{206} \mathrm{~Pb} /{ }^{208} \mathrm{~Pb}$ and ${ }^{206} \mathrm{~Pb} /{ }^{207} \mathrm{~Pb}$ ratios of total digests of soil from Jian'Ou are 0.4784 and 1.1864, respectively while that from Anxi are 0.4850 and 1.2032 . But there are exceptions. Due to the nature of soil or the difference in lead isotopic ratios caused by pollution, there is little difference between lead isotopic ratios from adjacent areas such as Fu'An and Fuding, Longyan and Zhangpu, Wuyi Moutain and Jian'Ou.

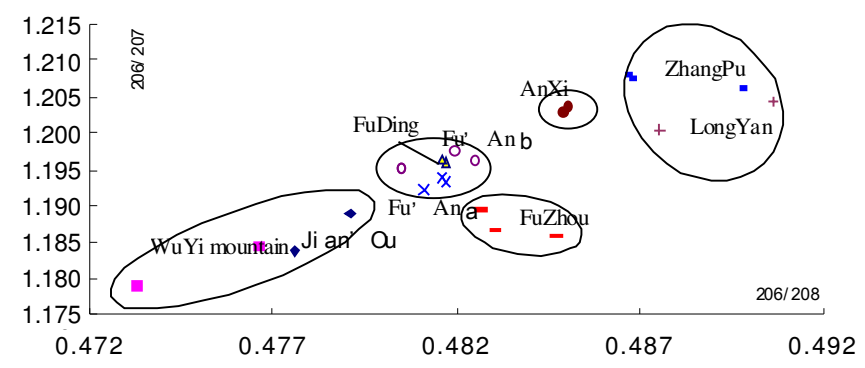

Fig. 1. Distribution of $\mathrm{Pb}$ isotopic ratios of total digests of soil fractions from different regions

In order to investigate this problem, the lead isotopic ratios of residual fractions in extracted soil samples are measured and the results are illustrated in Table-2, from which we can see the lead isotopic ratios of residual fraction has advantageous distinguishability. The differences that cannot be distinguished in Table-1 now can be done by isotopic ratios of residual fraction except the ratios difference between Fu'an and Fuding because these two areas are very close. Comparing Fig. 2 with Fig. 1, 
we can find the remarkable difference between lead isotopic ratios of residual fraction and that of total digests of soil fractions. Take Longyan for example, the average ${ }^{206} \mathrm{~Pb} /{ }^{208} \mathrm{~Pb}$ and ${ }^{206} \mathrm{~Pb} /{ }^{207} \mathrm{~Pb}$ ratio of total digests are 0.4891 and 1.2024 while those of residual fraction are 0.492 and 1.2101. The above remarkable difference between the lead isotopic ratios of residual fraction and total digests of soil fractions indicates that the lead in soil not only comes from the original soil but also from outside environment as a result of considerable pollution. This kind of lead pollution mostly retains in the surface layer and can hardly soak into the mine crystal lattice configuration in soil because of its little content in deeper soil layer. The lead isotopic form is mainly determined by the natural factors such as geologic configuration, not by extraneous pollution. It is obviously the lead isotopic ratios of residual fraction have much more distinct regional characteristic than that of the total digests because the former one contains HF which can extract the lead from mine crystal lattice configuration.

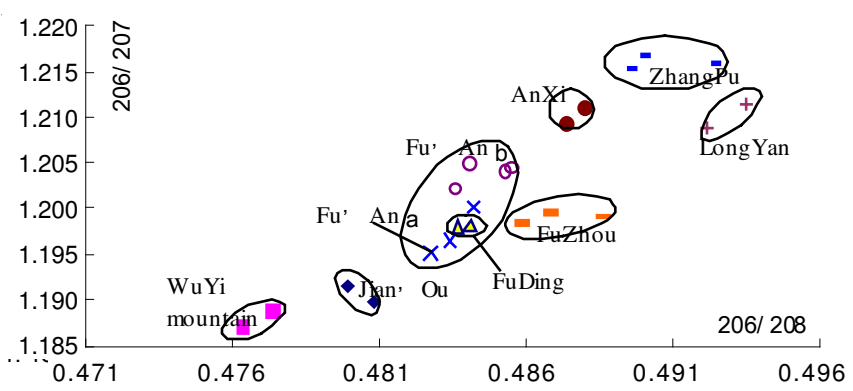

Fig. 2. Distribution of $\mathrm{Pb}$ isotopic ratios of soil residual fraction from different regions

\section{Conclusion}

Lead isotopic ratios vary with geographic location. In this study, lead isotopic ratios of soil from different regions in Fujian Province were determined by inductively coupled plasma mass spectrometry (ICP-MS) and then the differences are compared. The results show that lead isotopic ratios in residual fractions has advantage to be free from the blur in lead isotopic ratios difference caused by pollutions. Therefore the regional difference of lead isotopic ratios of the residual fractions can be regarded as an important gist to identify source of soil.

\section{REFERENCES}

1. N.C. Munksgaard, G.J. Batterham and D.L. Parry, Marine Pollut. Bull., 36, 527 (1998).

2. V.J. Stukas and C.S. Wong, Science, 211, 1424 (1981).

3. D. Amarasiriwardena and R.M. Barnes, Fresenius J. Anal. Chem., 362, 493 (1998).

4. Z.Y. Huang, M.F. Yang, Z.X. Zhuang, X.R. Wang and S. Frank, Chin. J. Anal. Chem., 31, 1036 (2003).

5. Z.Q. Cheng and K.A. Foland, Appl. Geochem., 20, 353 (2005).

6. A. Tessier, P.G.C. Campbell and M. Blsson, Anal. Chem., 51, 844 (1979).

7. M. Viczian, A. Lasztity and R.M. Barnes, J. Anal. At. Spectrom., 5, 293 (1990).

8. C. Latkoczy, T. Prohaska, G. Stingeder and M.T. Nicola, J. Anal. At. Spectrom., 13, 561 (1998). 